\title{
FORMAÇÃO EM PSICOLOGIA E A APROPRIAÇÃO DO ENFOQUE DA ATENÇÃO PRIMÁRIA À SAÚDE EM FORTALEZA, CEARÁ
}

\author{
TRAINING IN PSYCHOLOGY AND THE APPROPRIATION OF THE FOCUS ON PRIMARY HEALTH \\ CARE IN FORTALEZA, CEARÁ
}

\author{
Lidiany Alexandre Azevedo ${ }^{1}$ \\ Daniely Ildegardes Brito Tatmatsu ${ }^{2}$ \\ Pedro Henrique Rocha Ribeiro ${ }^{3}$
}

\begin{abstract}
Resumo As mudanças econômicas e sociais ocorridas no Brasil na década de 1980 e a garantia de políticas públicas pela 'Constituição Cidadã' ocasionam o início de uma transformação no campo psi: a inviabilidade do modelo de profissional autônomo e a abertura de novos campos de atuação. Dentre estes, a Saúde Coletiva, em seus três níveis de atenção, é a que mais tem possibilitado essas novas formas de inserção. No entanto, o processo de interlocução dos psicólogos com esse campo do saber vem sendo problemático e remete a uma formação que ainda não tem fornecido a preparação necessária para a atuação em consonância com o Sistema Único de Saúde (SUS). Este trabalho teve como objetivo analisar a proposta de formação, para a atuação na atenção primária, prevista pelos cursos de graduação em psicologia de Fortaleza, Ceará, por meio dos seus projetos político-pedagógicos. Para isso usou-se uma abordagem qualitativa, tendo como estratégia metodológica a análise documental. Constatou-se que a formação do psicólogo, apesar das novas diretrizes curriculares, ainda é pautada por uma proposta clínica tradicional, com ensino centrado no modelo intervencionista de saúde. Conclui-se apontando a necessidade de mudanças que ampliem e requalifiquem a formação em psicologia para atuação em Atenção Primária à Saúde.
\end{abstract}

Palavras-chave formação; psicologia; atenção primária.
Abstract The socioeconomic changes that took place in Brazil in the 1980s and the guarantee of public policies by the 'citizen constitution' sparked a transformation in the psi field: the impracticability of the self-employed worker model and the opening of new fields of performance. Among these, Public Health, on its three levels of care, is what has enabled these new forms of integration the most. However, the psychologists' process of dialogue with this field of knowledge has been problematic, a fact that has lead to a type of training that has not provided the necessary readiness for them to work in line with SUS. This article aims to analyze the proposal of training professionals to work in primary care as foreseen under the undergraduate programs in psychology in Fortaleza by means of its political and educational projects. To achieve this, the authors used a qualitative approach and document analysis as their methodological strategy. It was found that, notwithstanding the new curriculum guidelines, psychologists are still trained based on a traditional clinical proposal, with education centered on the intervention model of health. The authors conclude there is a need for changes designed to expand and re-qualify the training in psychology to work in primary health care.

Keywords training; psychology; primary care. 


\section{Introdução}

Partindo da compreensão de que os campos de atuação da psicologia vêm se diversificando e aumentando a cada dia, considera-se que isso requer um comprometimento acerca da reflexão e produção de novos conhecimentos, assim como a responsabilidade de se pensar a sua prática e tentar realizá-la de maneira contextualizada. Dessa forma, concorda-se com Nepomuceno (2007, p. 10) quando diz que “a Psicologia deve se constituir como uma ciência necessariamente situada, comprometida com a realidade".

Diante desse cenário, na disciplina anual de pesquisa do curso de psicologia da Universidade Federal do Ceará (UFC), optou-se por realizar um estudo que pudesse contribuir para o debate sobre a "Formação em psicologia e Atenção Primária à Saúde", pois, como se sabe:

Especificamente em relação aos trabalhadores para esse setor, vamos encontrar na Constituição Nacional que cabe ao SUS ordenar a formação de recursos humanos na área de saúde. Na Lei Orgânica da Saúde, o título relativo aos recursos humanos assevera que a política para os trabalhadores da área deve cumprir o objetivo de organizar um sistema de formação em todos os níveis de ensino (Ceccim e Feuerwerker, 2004, p. 1.401).

Dado o pouco tempo de existência da Carta Magna brasileira, e portanto também do Sistema Único de Saúde (SUS), compreende-se que se iniciou um processo de mudança sobre a visão restrita de saúde, oficialmente no campo da formação profissional, muito recentemente, o qual se fortaleceu com a oportunidade de transformação da educação nacional, por meio do debate sobre a formulação da Lei de Diretrizes e Bases da Educação, LDB n. 9.394/96, e das Diretrizes Curriculares Nacionais (DCN).

Um dos fatores que movem esta pesquisa é a concordância com a 'evocação' de Ceccim e Feuerwerker (2004) sobre a necessidade de se ter como norteador da formação profissional em saúde o princípio da integralidade 4 da atenção em saúde. Assim, busca-se contribuir para o desenvolvimento das teorias e práticas da psicologia ante a edificação de um sistema único e público de saúde que efetivamente proporcione integralidade à atenção à saúde, sem se confundir com a totalidade (Mattos, 2006).

Propõe-se avaliar como os graduandos estão sendo formados para o exercício de suas atividades e o grau de consonância dessa formação com as necessidades da Atenção Primária à Saúde e do SUS. Salienta-se que, como estudantes de psicologia e partícipes da primeira turma curricular que experimenta a inserção desse novo olhar a respeito da saúde no currículo de psicologia da UFC, bem como bolsistas do Programa de Educação pelo Trabalho para a Saúde (PET-Saúde/MS e MEC), tem-se interesse em estabelecer 
um olhar mais crítico e aprofundado sobre as propostas de ensino das habilidades e competências no que tange às exigências sociais para o desenvolvimento da Atenção Primária à Saúde pela psicologia.

O objetivo principal deste trabalho foi analisar, com base nos projetos político-pedagógicos (doravante denominados PPP) dos cursos de graduação em psicologia de Fortaleza, a formação dos estudantes em Atenção Primária à Saúde.

\section{A psicologia e a sua relação com as políticas públicas de saúde do Brasil}

A profissão de psicólogo foi regulamentada em 1962, porém, mesmo antes da regulamentação, já havia estudos e algumas práticas caracterizadas pelo olhar único para a clínica, a escola e a organização, com o predomínio eminente da primeira. Daí, já se traçava um perfil da formação em psicologia, de um profissional liberal, "moldado à luz das profissões médicas" (Yamamoto, 2003, p. 40).

Em decorrência da crise econômica que o país passou na década de 1980, a demanda do psicólogo, como profissional autônomo, que diminui consideravelmente, e o novo campo de atuação que se abria no setor de bem-estar social, por meio das políticas públicas garantidas pela Constituição de 1988, são fatores que apontam para uma necessária mudança de perfil desse especialista (Dimenstein, 1998).

Assim, a Saúde Coletiva, em seus três níveis de atenção, é um dos campos em que a psicologia se insere e que, atualmente, mais têm demandado sua atuação. O ingresso se dá no final da década de 1970 e início da década de 1980, no momento em que se tem na saúde o modelo médico assistencial privatista e uma prática curativista (Dimenstein, 1998). A entrada nesse contexto sócio-histórico vai acarretar o delineamento de características comuns dos psicólogos que iniciaram a entrada da psicologia em instituições públicas de saúde. Essas características, por vezes ainda encontradas nas práticas de alguns, resumem-se num profissional que tende a não ter uma perspectiva ampliada de saúde e a não pensar acerca da qualidade de vida da população como uma das prioridades do processo saúde-doença.

Entretanto, deve ser enfatizado que o Brasil, nesse período, passou por diversas mudanças socioeconômicas, as quais acarretaram dificuldades na assistência à saúde da população, pautada pelo modelo médico assistencial privatista, curativo, individual - além de ter a maior gama de seus serviços prestados por entidades privadas, "os serviços médicos eram pagos por Unidade de Serviço (US)" (Escorel, Nascimento e Edler, 2005, p. 61). Essa assistência à saúde, de responsabilidade do Instituto Nacional de Previdência Social (INPS), vinha perdendo sua eficiência e qualidade e 
funcionando como uma incontrolável fonte de corrupção, ocasionando as primeiras tentativas de alteração nas políticas públicas de saúde, iniciativa de técnicos, do movimento sanitário e de movimentos sociais (Polignano, 2009; Andrade, 2007).

Nos anos 1980, esse quadro se mantém, tornando inadiável uma reformulação do sistema. Nesse período, voltam a se articular os movimentos sociais, que passam a lutar por mudanças que possam solucionar esses problemas, e profissionais da saúde de diversas categorias, dentre eles médicos, acadêmicos e cientistas, discutem o desgaste da qualidade de vida da população (Fleury, 1997). Nesse contexto, em que emerge o clamor por uma reformulação da assistência à saúde como uma essencial Reforma Sanitária, ocorre a aliança entre movimentos sociais e técnicos da saúde, nascendo o movimento sanitário - caracterizado como uma força política, que buscava a transformação do setor saúde e tendo atuado "como liderança do processo de reformulação do setor saúde" (Escorel, Nascimento e Edler, 2005, p. 68).

Com a volta do período democrático, lideranças do movimento sanitário adquirem posições importantes nas instituições encarregadas pela política de saúde no país. O ponto culminante de toda essa luta foi a convocação e a realização da $8^{a}$ Conferência Nacional de Saúde (1986), que contou com o envolvimento da sociedade em suas deliberações e que se diferenciou das anteriores por não ter funcionado apenas como um mecanismo de controle do Estado. Nela, foram apresentadas as noções básicas da Reforma Sanitária:

Concepção ampliada de saúde, entendida numa perspectiva de articulação de políticas sociais e econômicas; Saúde como direito de cidadania e dever do Estado; Instituição de um Sistema Único de Saúde que tem como princípios fundamentais a universalidade, a integralidade das ações, a descentralização e hierarquização dos serviços de saúde; Participação popular e controle social dos serviços públicos de saúde (Dimenstein, 1998, p. 62).

Ainda foi aprovada “a criação de um sistema único de saúde, que se constituísse num novo arcabouço institucional, com a separação total da saúde em relação à previdência" (Cordeiro, 2004; Dimenstein, 1998).

Em 1988 foi promulgada a Constituição Cidadã, que oficializava a criação do novo sistema de saúde, o SUS. Porém, no ano seguinte continuavam as discussões para a formulação da lei complementar que daria bases operacionais à reforma, a Lei Orgânica da Saúde (LOS). Principiava-se a construção do SUS.

O conceito de saúde passa a ser visto de modo ampliado: a saúde não é mais apenas a ausência de doença; entende-se que há múltiplos e complexos fatores que influenciam esse processo de saúde-doença. Assim, não se poderia continuar restringindo o trabalho dos profissionais da saúde a ambu- 
latórios e hospitais especializados e gerais (Nepomuceno, 2007). Toda essa crise fez com que se voltasse o olhar para a atenção primária, pois ela seria capaz de "levar a atenção à saúde o mais próximo possível do local onde as pessoas vivem e trabalham, constituindo o primeiro elemento de um processo de atenção continuada à saúde" (Starfield, 2002, p. 30) e, assim, considerar os outros determinantes do processo saúde-doença (ambiente físico, psicológico e social). Vale enfatizar que outro ponto de grande relevância no primeiro nível de atenção, talvez o que o distinga e o represente melhor, é a integralidade.

\section{A opção pelo termo 'atenção primária'}

Aqui, faz-se necessário conceituar Atenção Primária e Atenção Básica, expressões que, rotineiramente, aparecem de maneira indistinta em boa parte da literatura. A Atenção Primária teve suas discussões iniciadas com a Conferência Internacional sobre Cuidados Primários de Saúde, a qual trouxe o apelo, aos governos, da implantação dos Cuidados de Saúde Primários (Declaração de Alma-Ata, 2009) como uma forma de reorientar a assistência à saúde, atendendo às principais necessidades e problemas de saúde da população. Corresponde à entrada no sistema para todas as novas necessidades e problemas, fornecendo atenção à pessoa no decorrer do tempo e a quase todas as situações de saúde, sendo uma abordagem preventiva e promocional, integrada com outros níveis de atenção e construída de forma coletiva com outros profissionais de saúde (Andrade, Barreto e Bezerra, 2006).

A Atenção Básica é caracterizada como um conjunto de ações de saúde, no âmbito individual e coletivo, que abrange a promoção, a prevenção, o diagnóstico, o tratamento, a reabilitação e a manutenção da saúde. É desenvolvida de forma democrática e participativa, na forma de trabalho em equipe, dirigida a populações de territórios bem delimitados, considerando o dinamismo existente no território em que vivem essas populações (Brasil, 2009).

Atenção Primária é um termo utilizado pela Organização Pan-Americana da Saúde (2005) e aceito internacionalmente, sendo considerado como porta de entrada do sistema. Entretanto, devido à forma como tem sido historicamente implantada em alguns países, em posição contrária aos seus princípios, recebeu várias críticas, o que pode ter exercido alguma influência na criação, pelo Ministério da Saúde, do termo Atenção Básica, que foi acrescido de alguns princípios a mais que a Atenção Primária.

Ambas as definições, na atualidade, defendem os mesmos princípios, sendo empregados por muitos autores como sinônimos, ou seja, atenção básica aparece como nomenclatura brasileira para a atenção primária. Porém, a 
concepção de Atenção Primária ainda é a que predomina em nosso contexto científico (Gil, 2006), por isso a escolha por sua utilização neste trabalho.

\section{Formação em psicologia: limites e desafios para a atuação na Atenção Primária}

Sabe-se que o campo de atuação em instituições de Atenção Primária à Saúde tem, desde a tímida inserção da psicologia na saúde pública, se ampliado cada vez mais: Unidades Básicas de Saúde (UBS), Programa Saúde da Família (PSF) e, mais recentemente, no Núcleo de Atenção Integral na Saúde da Família (NASF), criado em 2005. Porém, a prática nesses equipamentos tem se mostrado bastante problemática (Benevides, 2005; Bernardes, 2007; Dimenstein, 1998; Lima, 2005; Yamamoto, 2003). Segundo Dimenstein (1998), essas dificuldades surgem devido à ação de transpor para esses equipamentos, de maneira simplista, o modelo de psicoterapia, o que ocasiona uma prática descontextualizada e inadequada, com baixos índices de qualidade e produtividade.

A literatura indica que essas dificuldades são consequências de uma formação acadêmica ainda centrada num modelo clínico hegemônico; deficiente no estabelecimento de relações com a realidade social local; baseada na junção de diferentes abordagens teóricas com a ilusão da constituição de uma unidade; num conhecimento segmentado e, por vezes, carente de uma reflexão crítica; que pouco dispõe de disciplinas que possam oferecer um mínimo de conhecimento sobre a Atenção Primária à Saúde, o SUS e os equipamentos de assistência à saúde (Bernardes, 2007; Lima, 2005). Assim, os estudantes concluem sua graduação e, sem outras oportunidades imediatas, entram no mercado de trabalho da saúde com uma concepção de saúde inadequada - curativa, hospitalocêntrica - para a realidade local e do sistema (SUS); sem um olhar sensível para os muitos determinantes do processo saúde-doença, sem comprometimento com as transformações sociais e sem o menor conhecimento para o trabalho no setor público. Daí encontramos profissionais que não dão importância à formação continuada; centrados apenas em seu trabalho, ou seja, sem a preocupação da realização de um trabalho multi/interdisciplinar; reprodutores de fazeres/técnicas descontextualizados do aparelho e da comunidade em que e com quem trabalham; com a concepção de uma prática assistencialista e, assim, descompromissados com os princípios do SUS de integralidade, universalidade e equidade.

Por isso, entende-se que a estrutura de formação dos cursos de graduação de psicologia não é organizada para a multiplicidade de centros de atuação, para o exercício de atividades dentro do setor público e principalmente 
para uma perspectiva mais ampla da saúde, característica essencial para o trabalho na Atenção Primária à Saúde. De acordo com Bock et al. (1984),

O mercado de trabalho atual precisa de gente que entenda de Saúde Pública, Saúde Mental, e a Universidade ainda está formando os profissionais liberais. A desqualificação existe pelo nível de ensino, mas é fundamentalmente uma desqualificação porque o tipo de profissional que está saindo das escolas não é aquele que o mercado precisa (Bock et al. 1984, p. 32).

Em pesquisa feita com psicólogos que atuam na rede pública de saúde, realizada pela Associação Brasileira de Ensino de Psicologia (Abep) no ano de 2006, verificou-se o quão deficiente tem sido a formação dos psicólogos para a atuação na Saúde Coletiva, principalmente na Atenção Primária à Saúde. As disciplinas e os estágios curriculares se restringem às abordagens clínicas; psicopatologias descontextualizadas, ou seja, que ainda insistem em trabalhar com um homem fragmentado, isolado dos meios em que estabelece múltiplas relações; práticas de intervenção intimistas; e, quando muito, estuda-se algo sobre a psicologia hospitalar. Porém, mais que estruturar os currículos, ofertando disciplinas que discutam sobre saúde mental, gestão de saúde, saúde pública, saúde coletiva e Programa Saúde da Família (PSF), residência, psiquiatria social, abordagem familiar, grupos, desenvolvimento comunitário, é necessário um corpo docente qualificado, que tenha conhecimento dos princípios do SUS; das novas políticas públicas da saúde; que valorize a oferta de serviços à comunidade; que seja capaz de dialogar sobre essa formação com os vários sujeitos envolvidos nesse processo, professores, alunos, usuários dos serviços, trabalhadores do sistema de saúde; e que seja capaz de estabelecer diálogos com os vários campos de interface da psicologia, levando os alunos a refletirem sobre todas essas questões (Bernardes, 2007).

Outro ponto que retrata a inadequada formação em saúde é percebido por meio dos serviços oferecidos pelos cursos de psicologia, que têm refletido a diversidade e a fragmentação da formação ainda marcada pela psicologia aplicada (Bernardes, 2007), ou seja, pelo uso de dados da psicologia na utilização de problemas práticos, baseados em um modelo único de atuação, centrado na intervenção individual. Assim, na maioria das universidades têm-se atividades pontuais e desconectadas oferecidas por núcleos de extensão e pelo serviço de clínica-escola.

Um novo modelo de formação profissional na área de saúde, tão urgente e demandado pela sociedade, já foi proposto pelos Ministérios da Saúde e da Educação por meio do Programa Nacional de Reorientação da Formação 
Profissional (Pró-Saúde), o qual trabalha na perspectiva de uma “abordagem integral do processo saúde-doença" (Brasil, 2007, p. 5), da promoção e da prevenção da saúde, bem como da integralidade das ações, ou seja, uma ação conjunta dos três níveis de assistência, primário (Atenção Básica), secundário (ambulatórios e hospitais especializados) e terciário (hospitais gerais). Isso se daria principalmente por meio da aprendizagem ativa, isto é, com a utilização de subsídios teóricos no ensino, em estágios, pesquisa e extensão.

Devido à ampla gama de significados dos termos prevenção e promoção e ao seu uso pelo senso comum, se faz necessário explicitar sua acepção para a saúde. Promoção, de acordo com o Ministério da Saúde, é uma das estratégias de produção de saúde, comprometendo-se com sujeitos e coletividades que expressem crescente autonomia e capacidade para gerenciar satisfatoriamente os limites e os riscos impostos pela doença, ampliando o entendimento do processo saúde/adoecimento (Brasil, 2009).

A Organização Pan-Americana da Saúde (Opas) diz que a prevenção lida com a modificação das condições subjacentes que levam à exposição a agravos à saúde em primeiro lugar, incorporando abordagens que criam a saúde e modificam as condições "que geram e estruturam a distribuição desigual das exposições que causam danos à saúde, as suscetibilidades da saúde e os recursos que protegem a saúde entre a população" (Opas, 2005).

Algumas instituições de ensino de psicologia, que já iniciaram a reflexão sobre a formação em saúde sobre a proposta do Pró-Saúde, repensando a forma de organização dos serviços, criaram os Serviços de Psicologia Aplicada (SPA), que visam integrar o conhecimento teórico com a prática, qualificando o aluno para o trabalho comunitário e de clínica ampliada com equipes multi/interdisciplinares, possibilitando o estágio nas mais diversas áreas da psicologia, de forma interligada, tentando considerar

a problematização do contexto, das demandas e da própria atuação profissional, pois se há algo a ser central na formação em Psicologia é a saúde da população, e aí articulam-se os problemas de aprendizagem, as relações de trabalho, sofrimento, relações familiares (Bernardes, 2007, p. 124).

Assim, entende-se que deve existir uma busca pela compreensão das necessidades dos usuários - práticas usuário-centradas -, tomando-a como um eixo central na formação, pois essas necessidades se constituem num dos principais objetivos da saúde, além de funcionar como um primordial mecanismo de integração dos distintos saberes dos profissionais da saúde (Ceccim e Feuerwerker, 2004).

Diante dessa realidade que se tem encontrado é que se faz necessário estudar a situação dos cursos de psicologia em relação à Atenção Primária à Saúde, e tomar como desafio a elaboração de currículos que levem em conta 
todas essas problemáticas, reorientando os psicólogos para esse e outros campos de atuação emergentes.

\section{Metodologia}

O presente trabalho consiste em uma pesquisa documental com tipologia exploratória com base em uma abordagem qualitativa. Esta perspectiva foi escolhida por melhor se adequar ao objetivo proposto: analisar a formação dos estudantes em Atenção Primária à Saúde dos cursos de graduação em psicologia de Fortaleza.

A opção por uma abordagem qualitativa se deu pelo "entendimento de que este tipo de escolha metodológica permite a investigação do objeto com base em sua dimensão histórica, o que torna possível estudar as ocorrências em sua provisoriedade, no seu dinamismo e na sua especificidade" (Martins, 2005, p. 47). Trata-se assim de uma investigação teórica que toma como base condições que explicam a realidade sem intervir diretamente, porém oferecendo possibilidade para futuras intervenções (Martins, 2005).

A pesquisa documental se dá pela utilização de documentos como única fonte de dados. Neste estudo, optou-se pelo uso dos PPP, por entendê-los como um processo permanente de reflexão e discussão e por acreditar-se que

o projeto busca um rumo, uma direção. É uma ação intencional, com um sentido explícito, com um compromisso definido coletivamente. Por isso, todo projeto pedagógico é, também, um projeto político por estar intimamente articulado ao compromisso sociopolítico com os interesses reais e coletivos da população majoritária. É político no sentido de compromisso com a formação do cidadão para um tipo de sociedade. Pedagógico, no sentido de definir as ações educativas e as características necessárias às instituições, de cumprirem seus propósitos e sua intencionalidade (Veiga, 1996, p. 13).

Assim, elegeu-se o reconhecimento da peculiaridade discursiva dos PPP e tomou-se como estratégia a análise documental, a qual retira dos documentos toda a análise e os dispõe de modo a realizar sua interpretação conforme os desígnios do que é proposto na pesquisa (Pimentel, 2001).

Para a compreensão do perfil do profissional psicólogo em formação na cidade de Fortaleza (Ceará), foram analisados três cursos de graduação em psicologia, dos quatro existentes, sendo um público e dois particulares. Além disso, tomaram-se como referência as DCN aprovadas pelo MEC para a área de psicologia (Brasil, 2004) e a legislação em saúde vigente no país, como os relatórios das Conferências Nacionais de Saúde e alguns artigos referentes à ordenação do sistema de saúde do Brasil. 
Entretanto, deve-se esclarecer que a escolha do objeto, PPP dos cursos de psicologia de Fortaleza, apresenta suas restrições, pois um curso particular foi aberto recentemente e por isso tem poucas condições de se autoavaliar, fazer uma análise crítica do perfil que está formando e propor, se necessário, modificações no seu projeto, além de não dispor ainda de projetos de pesquisa e extensão. Assim, com esses documentos analisou-se o modo como se pretende dar a formação desses estudantes.

De acordo com Pimentel (2001), a análise documental implica escolha do tipo de documento a ser analisado e reflete ideias e propósitos delimitados aprioristicamente. Por isso, a primeira etapa da pesquisa foi a definição do método de trabalho para a análise dos PPP, o qual ocorreu por meio da escolha de quatro termos que estivessem associados à Atenção Primária: promoção, prevenção, atenção básica e a própria atenção primária. A escolha destes se deu por serem termos que remetem a uma concepção teórico-prática que embasa a saúde pública no setor saúde no país.

A etapa seguinte destinou-se a encontrar as fontes, as quais foram obtidas nas coordenações de cada um dos cursos, após prévio contato e autorização dos seus respectivos coordenadores.

As fases ulteriores foram dedicadas à organização do material e ao tratamento dos dados. Assim, na terceira etapa realizou-se a leitura de todos os documentos e posteriormente dos registros que indicavam trechos com a presença das categorias definidas. Com a finalidade de organizar esse material elaboraram-se três quadros, um para cada curso, nos quais foram colocadas as citações referentes às categorias e sua relação com o ensino, a pesquisa e a extensão. Ainda nesse momento, atentou-se para os segmentos relacionados à organização da estrutura curricular referente à saúde contidos nos documentos, pois eles se mostraram relevantes para a interpretação. Por último, houve o estágio de tratamento dos dados, no qual se empregou a análise de todo o material destacado.

Faz-se necessário enfatizar dois pontos. O primeiro é que não se pretende fazer uma comparação entre os cursos, mas sim uma reflexão acerca de como vem se dando ou pretende se dar a formação em Atenção Primária à Saúde dos estudantes de psicologia, contribuindo para as discussões e avaliações dessas instituições de ensino. O segundo é que em razão de o objeto de estudo (os PPP) serem documentos curriculares, não se fez necessário submeter esta pesquisa ao Comitê de Ética em Pesquisa (CEP) da universidade, já que não foi envolvida uma relação direta com seres humanos, a qual é resguardada pela resolução n. 196/96 do Conselho Nacional de Saúde (Brasil, 1996b). 


\section{Resultados}

Neste tópico, encontra-se a descrição da terceira fase da análise documental. Os quadros 1, 2 e 3 são frutos da organização do material, contendo as citações referentes aos termos promoção, prevenção, atenção básica e atenção primária e sua relação única com a categoria ensino, pois todos os termos estavam relacionados a essa atividade, não havendo nenhuma referência nas esferas da pesquisa e da extensão.

\section{Quadro 1}

Citações do projeto político pedagógico (PPP) do curso de psicologia 1, formuladas em torno dos termos promoção e prevenção. Fortaleza, 2009.

\section{Ensino}

“...terá como ênfase a aplicação dos conhecimentos e técnicas de Psicologia na promoção da saúde"

"...que o capacite para o exercício profissional, com ênfase na promoção da saúde"

"...orientação e planejamento de ações de promoção social e da saúde"

“...intervenção em processos psicológicos e psicossociais com vistas à promoção social e da saúde"

"...conhecimentos, competências e habilidades necessárias para o trabalho de promoção social e da saúde"

“...com o objetivo de autoconhecimento, desenvolvimento pessoal, grupal e institucional, numa postura de promoção social e da saúde"

"...atuar profissionalmente em diferentes contextos, na promoção social e na promoção da saúde"

“...coordenar e intervir em processos grupais em diferentes contextos, visando à promoção da saúdee da qualidade de vida"

"Núcleo Psicologia e Processos Clínicos e de Promoção da Saúde"

"Atuação e aplicação de técnicas científicas em Psicologia, visando à prevenção eà promoção à saúde dos indivíduos, dos grupos e organizações"

"...experiência junto a diferentes populações e atenção nos níveis de promoção e prevenção" (duas vezes)

“...visando à saúde do trabalhador e à satisfação no trabalho para a elaboração e execução de projetos de

Promoção prevenção e promoção humana" (duas vezes)

"Atuação e aplicação de técnicas científicas em Psicologia, visando à prevenção e à promoção à saúde dos indivíduos, dos grupos e organizações"

"...possibilitando o enfrentamento seguro dos desafios postos ao profissional de Psicologia, promotor da saúde nos mais diversos locais"

"...enfatizando o seu papel na sociedade como promotor da saúde"

"...utilizar o conhecimento adquirido para promover a saúdejunto à sociedade"

\section{Ementas}

"Estratégias individuais e coletivas de promoção da saúdemental na atualidade" "Instrumentos de mediação simbólica como promotores de saúde mental"

"Perspectiva multidisciplinar na promoção da saúde mental"

"...articular ações que visem à promoção da saúde"

"...identificar sua contribuição na promoção da saúde"

“...discutir ações que possam viabilizar a promoção da saúde"

“...execução e avaliação de observação das relações humanas em ambientes psicossociais com vistas à promoção da saúde em diferentes contextos sociais" 


\section{Continuação - Quadro 1}

Citações do projeto político pedagógico (PPP) do curso de psicologia 1, formuladas em torno dos termos promoção e prevenção. Fortaleza, 2009.

\section{Ensino}

“...o domínio de conhecimentos psicológicos e a capacidade de utilizá-los em diferentes contextos que demandam a análise, avaliação, prevenção"

"...levantamento de necessidades e desenvolvimento de programas educacionais em diferentes organizações, objetivando medidas de prevenção"

"Atuação e aplicação de técnicas científicas em Psicologia, visando à prevenção eà promoção à saúde dos indivíduos, dos grupos e organizações"

“...experiência junto a diferentes populações e atenção nos níveis de promoção e prevenção"

"...visando à saúde do trabalhador e à satisfação no trabalho para a elaboração e execução de projetos de prevenção e promoção humana"

"Atuação e aplicação de técnicas científicas em Psicologia, visando à prevenção eà promoção à saúde dos indivíduos, dos grupos e organizações"

Prevenção "...experiência junto a diferentes populações e atenção nos níveis de promoção e prevenção"

“...visando à saúde do trabalhador e à satisfação no trabalho para a elaboração e execução de projetos de prevenção e promoção humana"

"...atuar profissionalmente em diferentes níveis de intervenção, de caráter preventivo ou terapêutico"

\section{Ementas}

"Pesquisa, prevenção e intervenção em problemas comunitários"

"Proporcionar ao estudante a vivência de atividades de planejamento, execução e avaliação de observação em diferentes organizações visando à prevenção"

"...na área da saúde de forma preventiva e curativa" (duas vezes)

"...intervenção e avaliação de áreas preventivas e terapêuticas em hospitais, unidades de saúde e ambulatórios"

“...procedimentos de diagnóstico, intervenção e avaliação de áreas preventivas e terapêuticas em hospitais, unidades de saúde e ambulatórios"

\section{Quadro 2}

Citações do projeto político pedagógico (PPP) do curso de psicologia 2, formuladas em torno dos termos promoção e prevenção. Fortaleza, 2009.

\section{Ensino}

Promoção Ementa

“...na elaboração, proposição e execução das políticas públicas na promoção da saúde psíquica"

Prevenção "O profissional de psicologia será capaz de atuar de forma preventiva e terapêutica"

"...atuar profissionalmente, em diferentes níveis de ação, de caráter preventivo ou terapêutico, considerando as características das situações e dos problemas específicos com os quais se depara"

"A compreensão e interpretação de processos intrapessoais e interpessoais na área clínica e da saúde, de forma preventiva e curativa" (três vezes) 
Quadro 3

Citações do projeto político pedagógico (PPP) do curso de psicologia 3, formuladas em torno dos termos promoção, prevenção e atenção primária. Fortaleza, 2009.

\section{Ensino}

"...estratégias clínicas deverão estar integradas às ações de caráter preventivo e de promoção de saúde"

"...tendo em vista a promoção da qualidade de vida dos indivíduos, grupos, organizações e comunidades"

"...os profissionais devem estar aptos a desenvolver ações de prevenção, promoção, proteção e reabilitação da saúde psicológica e psicossocial"

“Desenvolve programas e projetos na área de saúde mental do trabalhador, visando à promoção de bemestar no trabalho"

"Realiza atividades variadas tais como diagnósticos, intervenções e avaliações de processos psicossociais,

Promoçăo visando à promoção do desenvolvimento humano"

"No texto da Reforma coloca-se explicitamente a promoção de políticas de ações afirmativas a serem implementadas nas universidades, especialmente nas instituições públicas"

"Essas políticas são direcionadas à promoção de ações que não apenas favoreçam o ingresso das populações historicamente excluídas das oportunidades de acesso à universidade"

"...contribuindo para a melhoria da qualidade de vida através de ações de caráter preventivo e de promoção da saúde"

“...estratégias clínicas deverão estar integradas às ações de caráter preventivo e de promoção de saúde" "...os profissionais devem estar aptos a desenvolver ações de prevenção, promoção, proteção e reabilitação da saúde psicológica e psicossocial"

"Essa atuação se dá nos planos individual, grupal e institucional, nas perspectivas preventiva e curativa" "Contribui no desenvolvimento de programas de atenção primária e outros de caráter preventivo e na elaboração e implementação de políticas de saúde"

Prevenção "Atua junto à equipe profissional, em atividades preventivas e de reabilitação, subsidiando-as quanto a aspectos psicossociais"

"...em diferentes níveis de intervenção, de caráter preventivo e/ou pedagógico"

"...relacionamento acadêmico e orientação profissional em uma vertente predominantemente preventiva"

"...contribuindo para a melhoria da qualidade de vida através de ações de caráter preventivo e de promoção da saúde"

"Etiologias e sua prevenção"

"Medicina comportamental e novas possibilidades de atuação preventiva"

Atenção "Contribui no desenvolvimento de programas de atenção primária e outros de caráter preventivo e na

Primária elaboração e implementação de políticas de saúde"

De acordo com a investigação da presença dos quatro termos nos PPP, o curso 1 apresentou 25 citações com o termo promoção e 15 citações com o termo prevenção; o curso 2, uma citação sobre promoção e cinco citações sobre prevenção; o curso 3, oito sobre promoção e dez sobre prevenção. Os demais termos, atenção primária e atenção básica, não são utilizados nos PPP, à exceção do curso 3, que fez uma referência ao termo atenção primária. 
Com relação à organização da estrutura curricular pertinente à saúde, a análise foi focada nas ênfases curriculares, nos serviços de clínica-escola e na forma como essas atividades foram ofertadas. Porém, optou-se pela realização apenas da interpretação dos dados trazidos, não se utilizando quadros.

Mereceu destaque o número de ênfases curriculares e de disciplinas referentes à Saúde Coletiva de cada um dos cursos. O curso 1 apresenta como possibilidade de aprofundamento as ênfases de Psicologia e Processos de Saúde e Psicologia e Processos Sociais e Comunitários, tendo uma disciplina de Saúde Coletiva e a possibilidade de realização de dois estágios em Saúde Coletiva.

O curso 2 apresenta três ênfases: Processos Educativos e Sociais; Processos Clínicos e Intervenções em Saúde e Processos de Gestão e Saúde no Trabalho; entretanto, não há disciplinas em Saúde Coletiva.

O curso 3 conta com duas ênfases: Processos Psicossociais e a Construção da Realidade e Processos Clínicos e Atenção à Saúde, tendo duas disciplinas de Saúde Coletiva. Os dois estágios obrigatórios da ênfase Processos clínicos e atenção à saúde podem ser desenvolvidos em Saúde Coletiva.

Verificou-se que dos três serviços de clínica-escola dos cursos, que atendem a população de modo geral, apenas o curso 2 está conveniado ao SUS, o qual deve se constituir como campo de prática para o ensino, pesquisa e extensão dos profissionais da saúde. Assim, a vivência da prática da atenção em rede, com base na integralidade entre os níveis de complexidade da assistência, nos outros cursos tende a ser deficiente.

É importante mencionar que o curso 1 apresenta a peculiaridade de não ter ainda nenhuma turma em estágio curricular, portanto, o seu PPP apresenta o planejamento da realização de estágios e projetos em um Centro de Formação em Psicologia, no qual também não é mencionada a relação com a rede de atenção à saúde.

Em nenhum dos documentos foi mencionada a realização de atividades usuário-centradas ou mesmo atividades voltadas para a educação em saúde e gestão compartilhada, o que caracteriza a pouca relevância dada ao controle social nas práticas oferecidas por essas instituições e na formação dos estudantes. Isso evidencia a deficiência no estabelecimento de uma relação ensino-serviço-comunidade, ou seja: os centros de formação analisados detiveram-se prioritariamente nos dois primeiros constituintes dessa ligação, que se apresentam mais simples por não envolver um elemento tão heterogêneo quanto à comunidade.

Até aqui, priorizou-se a apresentação dos dados encontrados nos PPP. Segue-se, na discussão, com o tratamento destes por meio de sua análise, tomando-se como referência as DCN de psicologia e a legislação em saúde vigente no país. 


\section{Discussão}

Os poucos elementos descritos nos PPP que apontam para uma interlocução com o campo da Saúde Coletiva sugerem que não há significativos avanços na construção de uma formação em consonância com os ideais do SUS e com as necessidades dos serviços e dos usuários, nos cursos de psicologia analisados e nos cursos de saúde de forma geral.

Pode-se perceber, pelos resultados encontrados, a predominância do uso dos termos promoção e prevenção, a quase ausência do termo atenção primária e a falta da expressão atenção básica. A análise dos documentos verificou que os termos que mais apareciam - promoção e prevenção - permitiam sua utilização em vários contextos e foram usados de maneira mais ampla nos PPP, como o ato de promover algo e como um modo de ver antecipado/preventivo e/ou precaução, ou seja, não se referiam ao seu significado no contexto da saúde (já abordado no referencial teórico).

Outro ponto evidente é a grande concentração desses termos no ensino e a deficiência na pesquisa e na extensão. Dessa forma, pode-se supor a possível inexistência ou o pequeno desenvolvimento de projetos de pesquisa e extensão voltados para o tema. Deve-se lembrar que os PPP não são documentos definitivos; ao contrário, têm um caráter dinâmico, possibilitando mudanças que estejam de acordo com os interesses e necessidades acadêmicas e da sociedade. Também deve-se lembrar que a extensão e a pesquisa, em geral, não fazem parte da matriz curricular, podendo ser ou não citadas nesses documentos.

Com base nesses dados, é possível pensar que a existência, ainda que relativamente pequena, desses termos e a sua concentração no ensino se configuram como uma forma de resposta às exigências sociais e ao controle social. 5 Portanto, esta pode ser uma maneira de se posicionar em consonância com as necessidades sociais, levando em consideração a possibilidade de construção de conhecimento com base nos distintos cotidianos de saúde, assim como de se acatarem as recomendações das $\mathrm{DCN}, 6$ início do processo de resposta às pressões sociais por mudanças na formação, que deixa claro "que o conceito de saúde da saúde coletiva e os princípios e diretrizes do SUS são elementos fundamentais a serem enfatizados na articulação da política de educação superior com a política de gestão da saúde" (Ceccim, Armani e Rocha, 2002, p. 381).

Ao se analisarem as matrizes curriculares dos cursos, com as ementas das disciplinas como recursos, notou-se a hegemonia da visão procedimentocentrada, por meio da relevância dada aos métodos de intervenção em detrimento da compreensão dos determinantes macros da saúde. O grande número de disciplinas voltadas para uma atuação clínica evidencia o quanto as oportunidades de aprendizagem estão centradas nesse campo de atuação. 
O ensino ainda aparece compartimentado, ou seja, com disciplinas essencialmente teóricas, outras práticas e poucas teórico-práticas, apesar de os PPP referirem o esforço dos cursos em levar a prática a todas as disciplinas, por meio de problematizações de casos, por exemplo.

Outra questão é a falta de integração dos serviços e das disciplinas relacionadas diretamente à saúde, disciplinas voltadas para a prática psicológica nos três níveis de atenção. As práticas destas, em seus respectivos campos, são realizadas de maneira fragmentada, existindo um espaço determinado para cada, impossibilitando o estágio nas mais diversas áreas da psicologia, de forma interligada, desconsiderando as demandas e a problematização da própria atuação profissional.

Os cursos elaboram suas práticas (de trabalho e ensino) de modo que aqueles que deveriam ser tomados como centro do serviço/atendimento são colocados em segundo plano, ou seja, numa posição de coadjuvantes do processo, os que serão beneficiados com uma nova ação oferecida pelo saber vindo da universidade e definida a priori como necessária. Essa configuração faz emergir outra dificuldade: a hierarquia entre a educação e os equipamentos de assistência, em que um se apresenta prioritariamente como o local do conhecimento e o outro como o espaço de prática, refletindo na formação desses futuros profissionais e ocasionando uma ruptura entre teoria e prática.

O distanciamento da universidade das diversas realidades de saúde produz um conhecimento que se torna inócuo pela sua inadequação à população. Assim, deveria haver a preocupação em se propiciar uma aprendizagem que respeitasse os saberes não profissionais (saber popular), ou seja, que estabelecesse uma cultura de relação com as classes populares e rompesse com a tradição autoritária e normatizadora da educação em saúde (Albuquerque e Stotz, 2004), compreendendo de maneira ampliada os determinantes do processo saúde-doença e capacitando na própria formação acadêmica os profissionais para a prática da integralidade, característica fundamental do SUS.

Esses dados deixam evidente a dissonância entre o que é proposto pelas DCN e os PPP dos cursos. Isso pode ter uma de suas justificativas no fato de as DCN se apresentarem apenas como uma recomendação, pois no Brasil a Lei de Diretrizes e Bases da Educação Nacional (LDB) garante autonomia às universidades - o que, para Ceccim e Feuerwerker (2004), tem ultrapassado seus limites, esquecendo a responsabilidade social da educação. O que se deve estabelecer é uma relação de parceria entre os responsáveis pela saúde e a educação.

A respeito de o artigo 43 da LDB estabelecer que a educação superior deva estimular o conhecimento dos problemas do mundo atual, prestar serviços à população de acordo com suas demandas, de modo a ter com ela uma relação de reciprocidade (Brasil, 1996a), não é isto que se observa nos cur- 
rículos e nas ementas dos cursos investigados, apesar de eles afirmarem em seus PPP sua adequação às questões regionais. Os usuários, como já dito, são vistos como beneficiários, e a comunidade aparece quase que unanimemente como apenas um campo de intervenção, não se levando em conta, por exemplo, o saber popular, nem a compreendendo como uma parceira para a contínua melhora do processo de formação para as realidades locais, regionais e nacional.

Porém, deve-se atentar que as universidades não podem ir contra a regulação política do Estado e os mecanismos legítimos de controle social, não por uma questão legal, mas pela sua legitimidade.

A relevância pública da saúde, definida constitucionalmente, deveria ser razão suficiente para que o setor da educação considerasse haver aí campo de exceção para acoplar a autonomia universitária à gestão das políticas públicas de saúde (Ceccim e Feuerwerker, 2004, p. 1.403a).

Fica visível que os elementos dos cursos de psicologia de Fortaleza, tratados aqui, corroboram a literatura, na qual se pode observar quão ausente é a discussão acerca de uma formação para o sistema de saúde vigente no país entre as graduações de saúde. Ceccim e Feuerwerker (2004) compartilham essa ideia, afirmando que o SUS é

sempre referido, criticado, e crivado de proposições espontâneas (...) carece de formulações construídas intelectualmente (...) desde as propostas conteúdo-curriculares. De outro lado, na educação, como setor específico das políticas públicas, não se observa a discussão da docência e do ensino-aprendizagem orientado para as profissões de saúde (Ceccim e Feuerwerker, 2004, p. 1.400).

Apesar da ausência de maiores discussões acerca das práticas pedagógicas e das formas de ensino-aprendizagem, no que concerne à formação de modo mais amplo, sabe-se que existem mecanismos legais (Constituição) e legítimos (fóruns em saúde) que orientam os cursos superiores em saúde, e os demais níveis de educação, para a formação de profissionais implicados com as necessidades de saúde, sobre os quais se torna importante discorrer aqui.

Como mecanismos legais, têm-se o artigo 200 da Constituição nacional, que afirma ser de responsabilidade do SUS a ordenação da formação de trabalhadores na área da saúde de modo geral (Pereira e Fracolli, 2009), e a Lei Orgânica da Saúde (LOS) de 1990, em seus artigos 6, 14 e 27, os quais frisam que os serviços de saúde devem funcionar como campos para o ensino-aprendizagem - e especificam como competências dos órgãos de gestão do SUS a criação e a implantação de políticas de formação e desenvolvimento de recursos humanos para a saúde, por meio de programas que 
visem tanto à realização de ensino e pesquisas na área da saúde como à educação continuada (Brasil, 1990).

Outra importante fonte de informações referente à formação dos profissionais de saúde é o controle social, importante mecanismo de legitimidade que se apresenta por meio de dois dispositivos, os conselhos de saúde (fóruns permanentes) e as conferências nacionais de saúde - CNS (convocadas a cada quatro anos). As CNS, de maior significação por se constituírem como um fórum de legitimação das políticas públicas de saúde e por se configurarem uma "arena democrática de debate" (Escorel e Bloch, 2005, p. 112), têm tido grande relevância na discussão acerca da formação dos profissionais. Destaca-se a sua oitava edição (1986), conhecida como um marco para a inserção do SUS na Constituição, que iniciou a discussão (em nível de controle social) sobre a adequação da formação dos profissionais da saúde de modo integrado e regionalizado ao sistema (Almeida e Ferraz, 2008).

As conferências seguintes - nona (1992), décima (1996) e décima primeira (2000) - continuaram debatendo essa temática. Nelas foram sugeridas a implantação de políticas de capacitação/formação profissional; a regulamentação do artigo 200 da Constituição e da Lei Orgânica da Saúde; a solicitação ao Ministério da Saúde de apresentação de um plano de ordenamento de capacitação, formação, educação continuada e reciclagem dos recursos humanos, dando importância ao controle social, com o intuito de ocorrer a integração ensino-serviço-comunidade; a inclusão no artigo 200 da Constituição nacional de critérios de avaliação dos cursos, bem como da relação entre a formação e as necessidades sociais em saúde (Almeida e Ferraz, 2008).

Devido aos problemas encontrados na formação e à dificuldade em se fazerem exercer as legislações referentes à formação dos profissionais, percebeu-se a necessidade de uma política para articular a educação e a saúde. Em 2005 foi publicada a portaria interministerial n. 2.118, que institui parceria entre o Ministério da Educação (MEC) e o Ministério da Saúde (MS) para cooperação técnica na formação e no desenvolvimento de recursos humanos na área da saúde, incentivando projetos e programas, a constituição de grupos de pesquisa e a promoção de eventos para socializar experiências e divulgar estudos e produção técnico-científica relacionados à formação de recursos humanos da área da saúde, além de reorientar a formação dos cursos de saúde para uma atuação qualificada no SUS (Brasil, 2005).

Apesar de todos esses mecanismos, fica claro, por meio da realidade da formação levantada no referencial teórico e dos dados obtidos nos PPP, o quanto a educação em psicologia ainda está à margem da discussão sobre a formação dos profissionais para a atuação no sistema de saúde vigente em nosso país, assim como até o momento não tem compreendido a necessidade de incorporar as características dele em sua matriz curricular. Somente agora, 
após as DCN e a abertura de campo de trabalho na Atenção Primária, é que a psicologia ensaia os primeiros passos para sua inserção no debate.

Um fator que ajuda a compreender essa questão e que se faz importante mencionar nesta discussão é a posição peculiar da psicologia em relação aos outros cursos que atuam na área da saúde, por algumas ocasiões estar presente nas ciências humanas e, em outras, nas ciências da saúde. Isso apresenta a vantagem de se manter um olhar para outros determinantes da doença que não só os biológicos, mas também os aspectos socioeconômicos, culturais e ambientais em que está inserido o sujeito. Entretanto, esse pertencimento a dois campos de conhecimentos acarretou uma posição marginal em algumas discussões, dentre elas a das políticas públicas de saúde, a qual emergiu somente com a necessidade de uma atuação mais adequada ao crescente palco de trabalho na saúde pública.

Por fim, deve-se ressaltar que as propostas interministeriais mencionadas não excluem a orientação para formação generalista presente nas DCN de psicologia. Como uma área de conhecimento múltipla, com axiomas divergentes e não integrados, fazem-se necessárias uma formação profissional que represente essa diversidade, baseada no ensino das diferentes perspectivas filosóficas e epistemológicas na interpretação do fenômeno psicológico; e uma formação generalista, com ênfase específica no último ano do curso (Bock, 1997).

\section{Considerações finais}

Com esta pesquisa, pode-se constatar que, mesmo com a recente reestruturação curricular, a formação do psicólogo ainda é permeada hegemonicamente por uma proposta clínica tradicional, ofertando uma relevância mínima às questões referentes ao sistema de saúde vigente no país, mesmo este se configurando, desde a década de 1980, como a área de maior abrangência entre os profissionais de psicologia.

Isso se torna evidente pelo reduzido número de disciplinas voltadas para Saúde Coletiva, especialmente as que abordam a Atenção Primária à Saúde. Da mesma forma, embora todos os cursos apresentem uma de suas ênfases curriculares em saúde, não é mencionada a relação com a rede de atenção à saúde. Apenas um dos cursos propõe como campo de estágio nessa ênfase o Serviço de Psicologia Aplicada conveniado ao SUS, o que representa um passo na direção da articulação com os demais equipamentos sociais em saúde. Os estágios dessas ênfases descritos nos PPP não se baseiam na concepção de ensino em serviço, pois não há menção à relação ensinoserviço-comunidade.

$\mathrm{Na}$ tentativa de preparar melhor os futuros profissionais de psicologia para uma atuação que caminhe em concordância com as diretrizes do SUS e 
as distintas realidades de saúde da população brasileira, deveriam ser realizadas algumas mudanças na busca de criação de um novo modelo de educação que tomasse por referência a constituição de redes de trabalho, de conhecimento para uma formação holística, abandonando a prática da simples aplicação dos conhecimentos psicológicos a outros campos de saberes.

Nesse sentido, novas estratégias, que vêm sendo desenvolvidas no campo da atuação profissional de saúde, podem ser incorporadas ao conjunto de ensinamentos responsáveis pela ampliação das habilidades e competências do futuro psicólogo. Ressaltam-se dentre as novas estratégias de atuação em saúde às aludidas, por exemplo, territorialização, (re)conhecimento do território na busca de compreender a 'produção social da saúde'; matriciamento, 'artifício pedagógico' e 'suporte técnico' de assessoramento aos trabalhadores de uma equipe interdisciplinar, sem formação nessa área, por meio de discussões de casos clínicos ou intervenções conjuntas; e prontuário transdisciplinar, construção das intervenções terapêuticas por meio do diálogo entre uma equipe multiprofissional, dando importância, além da dimensão biológica, aos aspectos subjetivos e sociais.

Acredita-se que propostas inovadoras como essas, uma vez inseridas no contexto do ensino, valorizadas pela pesquisa e a extensão, darão nova dinâmica no processo de solução das dificuldades encontradas na formação de psicologia na área de saúde.

Considera-se de grande relevância a realização de atividades práticas das disciplinas, estágios básicos e ênfase também na atenção primária à saúde. Merece destaque este último aspecto, pois a sua incorporação em estágios nos outros níveis de atenção à saúde, configurando uma prática em rede, permitiria uma formação mais abrangente, além de mais adequada para a compreensão do funcionamento do sistema de saúde.

Deve-se levar em conta ainda a necessidade de qualificação do corpo docente, investindo-se na aproximação de uma educação que integre os centros de ensino, os serviços de saúde e a comunidade, permitindo a formação dos estudantes e resguardando o compromisso social da universidade.

Por último, sugere-se a participação nas discussões e na construção das políticas públicas de saúde, principalmente as referentes à saúde mental, bem como ensino e práticas pautadas nas determinações dessas instâncias a fim de se estabelecer uma atuação mais crítica por meio do protagonismo social, e capaz de problematizar não apenas as questões do cotidiano mas também os seus mecanismos legais.

A opção pela elaboração de um conhecimento mais amplo perpassa pela aceitação da transformação constante; portanto, avaliar a formação em psicologia é um dever imprescindível, respeitada a necessidade de tempo para a experimentação considerável de nossas criações. 


\section{Agradecimento}

Não se poderia deixar de agradecer aos coordenadores dos cursos de graduação em psicologia, que forneceram os seus projetos político-pedagógicos para a realização desta pesquisa.

\section{Notas}

1 Psicóloga, graduada pela Universidade Federal do Ceará, Fortaleza, Brasil. <lidianyazevedo@gmail.com>

Correspondência: Av. Deputado Paulino Rocha, 50, casa 75, CEP 60864-311, Cajazeiras, Fortaleza, Ceará.

2 Professora assistente da Universidade Federal do Ceará e tutora do PET-Saúde, Fortaleza, Ceará, Brasil. Mestre em Ciências da Saúde pela Universidade Federal do Maranhão. $<$ danielybrito@gmail.com>

3 Graduando em Psicologia pela Universidade Federal do Ceará, Fortaleza, Brasil. <prvarella@gmail.com>

4 O conceito de integralidade pode ser definido em três campos diferentes: atuação dos profissionais da saúde, organização dos serviços e maneira de agir do governo em relação às questões de saúde. Apesar de seus distintos usos, apresenta uma característica capaz de englobar todos os conjuntos, a de ir contra a fragmentação, a especialização e o reducionismo, permitindo um diálogo entre os vários envolvidos, atores e níveis de serviços, no processo de atenção à saúde (Mattos, 2006).

5 É entendido como “uma participação política das entidades representativas da sociedade civil em órgãos, agências ou serviços do Estado responsáveis pelas políticas públicas na área social" (Valla, 1998, p. 10).

${ }^{6}$ As DCN surgem em substituição ao conceito de currículo mínimo para as profissões superiores, levando em conta a LOS, o relatório final da XI Conferência Nacional de Saúde, documentos da Organização Pan-Americana da Saúde (Opas) e Organização Mundial da Saúde (OMS) e as recomendações da Rede Unida de Desenvolvimento dos Recursos Humanos em Saúde (Rede Unida) (Costa e Miranda, 2009). 


\section{Referências}

ALBUQUERQUE, Paulette C. de; STOTZ, Eduardo N. A educação popular na Atenção Básica à Saúde no município: em busca da integralidade. Interface - Comunicação, Saúde, Educação, Botucatu-SP, v. 8, n. 15, p. 259 274, mar./ago. 2004.

ALMEIDA, Luciana P. G.; FERRAZ, Clarice A Políticas de formação de recursos humanos em saúde e enfermagem. Revista Brasileira de Enfermagem, v. 61, n. 1, p. 31-35, 2008.

ANDRADE, Luiz Odorico M. de. Do nascimento da saúde pública ao movimento préSUS. In: ANDRADE, Luiz Odorico Monteiro de; BARRETO, Ivana Cristina de Holanda Cunha (Orgs.). SUS passo a passo: história, regulamentação, financiamento, políticas nacionais. 2. ed. São Paulo: Hucitec, 2007. p. 25-35.

ANDRADE, Luiz O. M.; BARRETO, Ivana C H. C.; BEZERRA, Roberto C. Atenção Primária à Saúde e Estratégia de Saúde da Família. In: CAMPOS, Gastão W. et al. (Orgs.). Tratado de Saúde Coletiva. São Paulo: Hucitec; Rio de Janeiro: Fiocruz, 2006. p. 783-836.

BENEVIDES, Regina. A psicologia e o Sistema Único de Saúde: quais interfaces? Psicologia \& Sociedade, Porto Alegre, v. 17, n. 2, p. 7-13, 2005.

BERNARDES, Jefferson de Souza. A psicologia no SUS 2006: alguns desafios na formação. In: SPINK, Mary Jane Paris (Org.). A psicologia em diálogo com o SUS: prática profissional e produção acadêmica. São Paulo: Casa do Psicólogo, 2007, p. 105-128.

BOCK, Ana Mercês. Formação do psicólogo: um debate a partir do significado do fenômeno psicológico. Psicologia: Ciência e Profissão, Brasília, v. 17, n. 2, p. 37-42, 1997.

BOCK, Ana Mercês et al. Política educacional e formação profissional do psicólogo. Psicologia: Ciência e Profissão, Brasília, v. 4, n. 2, p. 24-33, 1984.
BRASIL. Lei n. 8.080, de 19 de setembro de 1990. Dispõe sobre as condições para promoção, proteção e recuperação da saúde, a organização e o funcionamento dos serviços correspondentes e dá outras providências. Diário Oficial da República Federativa do Brasil, Poder Executivo, Brasília, DF, 20 set. 1990, seção I, p. 18.054.

. Lei n. 9.394, de 20 de dezembro de 1996. Estabelece as diretrizes e bases da educação nacional. Diário Oficial da República Federativa do Brasil, Poder Executivo, Brasília, DF, 23 dez. 1996a, seção I, p. 27.839.

. Resolução n. 196, de 10 de outubro de 1996. Diretrizes e Normas Reguladoras de Pesquisas Envolvendo Seres Humanos. Diário Oficial da República Federativa do Brasil, Poder Executivo, Brasília, DF, 16 out. 1996b, seção 1, p. 21.082.

Parecer Conselho Nacional de Educação/Câmara de Educação Superior 0062/2004, de 19 de fevereiro de 2004. Estabelece as Diretrizes Curriculares Nacionais para o Curso de Graduação em Psicologia. Diário Oficial da República Federativa do Brasil, Poder Executivo, Brasília, DF, 18 maio 2004, seção 1, p. 16.

Portaria Interministerial n. 2.118, de 3 de novembro de 2005. Estabelece parceria entre o Ministério da Saúde e o Ministério da Educação. Diário Oficial da República Federativa do Brasil, Poder Executivo, Brasília, DF, 4 nov. 2005, seção 1, p. 112.

Associação Brasileira de Ensino de Psicologia. Ministério da Saúde. A psicologia em diálogo com o SUS: prática profissional e produção acadêmica [relatório final de pesquisa]. Brasília: Abep, 2006.

Ministério da Saúde. Ministério da Educação. Programa Nacional de Reorientação da Formação Profissional em Saúde Pró-Saúde: objetivos, implantação e desenvolvimento potencial. Brasília: Ministério da Saúde, 2007. 
. Ministério da Saúde. O SUS de A a Z: garantindo saúde nos municípios. 3. ed. Brasília: Ministério da Saúde, 2009.

CECCIM, Ricardo Burg; FEUERWERKER, Laura C. Macruz. Mudança na graduação das profissões de saúde sob o eixo da integralidade. Cadernos de Saúde Pública, Rio de Janeiro, v. 20, n. 5, p. 1400-1410, set./out.2004.

CECCIM, Ricardo Burg; ARMANI, Teresa Borgert; ROCHA, Cristianne Famer. O que dizem a legislação e o controle social em saúde sobre a formação de recursos humanos e o papel dos gestores públicos no Brasil. Ciência \& Saúde Coletiva, Rio de Janeiro, v. 7, n. 2, p. 373-383, 2002.

CORDEIRO, Hésio. O Instituto de Medicina Social e a luta pela Reforma Sanitária: contribuição à história do SUS. Physis - Revista de Saúde Coletiva, Rio de Janeiro, v. 14, n. 2, p. 343-362, 2004.

COSTA, Roberta Kaliny de Sousa; MIRANDA, Francisco Arnoldo Nunes de. Formação profissional no SUS: oportunidades de mudanças na perspectiva da Estratégia Saúde da Família. Trabalho, Educação e Saúde, Rio de Janeiro, v. 6, n. 3, p. 503-517, nov.2008/ fev.2009.

DECLARAÇÃO DE ALMA-ATA. Conferência Internacional sobre os Cuidados de Saúde Primários, Casaquistão, 1978. Disponível em: $<$ www.saudepublica.web.pt/05-Promocao Saude/Dec_Alma-Ata.htm>. Acesso em: 18 jan. 2009.

DIMENSTEIN, Magda Diniz Bezerra. O psicólogo nas unidades básicas de saúde: desafios para a formação e atuação profissionais. Revista Estudos de Psicologia, Natal-RN, v. 3, n. 1, p. 53-81, 1998.

ESCOREL, Sarah; BLOCH, Renata Arruda. As Conferências Nacionais de Saúde na construção do SUS. In: LIMA, Nísia Trindade et. al. (Orgs.). Saúde e democracia: história e perspectiva do SUS. Rio de Janeiro: Editora Fiocruz, 2005. p. 83-120.
ESCOREL, Sara; NASCIMENTO, Dilene Raimundo do; EDLER, Flavio Coelho. As origens da Reforma Sanitária e do SUS. In: LIMA, Nísia Trindade et al. (Orgs.). Saúde e democracia: história e perspectiva do SUS. Rio de Janeiro: Editora Fiocruz, 2005. p. 59- 81.

FLEURY, Sônia. A questão democrática na saúde. In: (Org.) Saúde e democracia: a luta do Cebes. São Paulo: Lemos Editorial, 1997, p. 26-42.

GIL, Célia Regina Rodrigues. Atenção Primária, Atenção Básica e Saúde da Família: sinergias e singularidades do contexto brasileiro. Cadernos de Saúde Pública, Rio de Janeiro, v. 22, n. 6, p. 1171-1181, 2006.

LIMA, Mônica. Atuação psicológica coletiva: uma trajetória profissional em Unidade Básica de Saúde. Psicologia em Estudo, Maringá-PR, v. 10, n. 3, p. 431-440, 2005.

MARTINS, Maria Tereza Cristina Torino Labigalini. Análise do projeto pedagógico da Faculdade de Enfermagem da PUC-Campinas à luz das políticas de saúde e de educação. Tese (Doutorado em Saúde Coletiva) - Faculdade de Ciências Médicas, Campinas, Unicamp, 2005.

MATTOS, Ruben Araujo de. Os sentidos da integralidade: algumas reflexões acerca de valores que merecem ser defendidos. In: PINHEIRO, Roseni; MATTOS, Ruben Araujo de (Orgs.). Os sentidos da integralidade na atenção e no cuidado à saúde. Rio de Janeiro: Cepesc/Uerj, IMS, Abrasco, 2006. p. 39-64.

NEPOMUCENO, Léo Barbosa. Contribuições da psicologia para intervenção social na Estratégia Saúde da Família do Sistema Único de Saúde: reflexões sobre uma caminhada. Monografia (Especialização Residência Multiprofissional em Saúde da Família) - Escola de Formação em Saúde da Família Visconde de Sabóia, Ministério da Saúde, Sobral, 2007.

ORGANIZAÇÃO PAN-AMERICANA DA SAÚDE (OPAS). ORGANIZAÇÃO MUNDIAL DA SAÚDE (OMS). Renovação da Atenção Primária 
de Saúde nas Américas. Washington: Opas, 2005.

PAIM, Jairnilson S.; ALMEIDA Filho, Naomar de. Saúde Coletiva: uma "nova saúde pública" ou campo aberto a novos paradigmas? Revista de Saúde Pública, São Paulo, v. 32, n. 4, p. 299-316, 1998.

PEREIRA, Juliana Guisardi; FRACOLLI, Lislaine Aparecida. A contribuição da articulação ensino-serviço para a construção da vigilância da saúde: a perspectiva dos docentes. Revista Latino-Americana de Enfermagem, Ribeirão Preto, v. 17, n. 2, p. 21-28, 2009.

PIMENTEL, Alessandra. O método da análise documental: seu uso numa pesquisa historiográfica. Cadernos de Pesquisa, São Paulo, n. 114, p. 179-195, 2001.

POLIGNANO, Marcus Vinícius. História das políticas de saúde no Brasil: uma pequena revisão. Disponível em: <www.medicina. ufmg.br/internatorural/arquivos/mimeo23p.pdf>. Acesso em: 16 set. 2009.
STARFIELD, Barbara. Atenção Primária: equilíbrio entre necessidades de saúde, serviços e tecnologia. Brasília: Unesco, Ministério da Saúde, 2002.

VALLA, Victor V. Sobre participação popular: uma questão de perspectiva. Cadernos de Saúde Pública, Rio de Janeiro, v. 14, supl. 2, p. 7-18, 1998.

VEIGA, Ilma P. A. (Org.). Projeto politicopedagógico da escola: uma construção possível. 2. ed. Campinas: Papirus, 1996.

YAMAMOTO, Oswaldo H. Questão social e políticas públicas: revendo o compromisso da psicologia. In: BOCK, Ana M. B. (Org.). Psicologia e compromisso social. São Paulo: Cortez, 2003, p. 37-54.

Recebido em 25/02/2010 Aprovado em 20/09/2010 